\title{
INTERFACES ENTRE A POLÍTICA HABITACIONAL E O PLANO DIRETOR PARTICIPATIVO
} NA METRÓPOLE FORTALEZA-CE

\section{Relations between the housing policy and participatory master plan in metropolis Fortaleza, Ceará, Brazil}

\author{
Elizete de Oliveira Santos \\ Doutoranda em Geografia, \\ Universidade Federal do Ceará, Fortaleza, Brasil \\ elizeoliver7@yahoo.com.br
}

Artigo recebido em 23/12/2012 e aceito para publicação em 18/08/2013

RESUMO: A questão habitacional aparece como elemento fundamental para compreender os processos de produção, apropriação e consumo do espaço urbano, lançando luz nas relações entre a segregação socioespacial e a especulação imobiliária que presidem a estruturação das cidades brasileiras. Este trabalho propõe-se a discutir as interfaces entre o Plano Diretor Participativo de Fortaleza (PDPFor) e a Política Municipal de Habitação (PHIS), visando contribuir para a reflexão da importância da integração das políticas urbana e habitacional. O texto estrutura-se em três partes: a primeira discute o contexto de emergência da "nova geração" de planos diretores no Brasil; a segunda reconstitui os processos de elaboração do PDPFor e da PHIS; e a terceira levanta um questionamento quanto ao diálogo entre as políticas urbana e habitacional, a partir da análise do conteúdo da PHIS e do capítulo da política de habitação do PDPFor.

Palavras-chave: política habitacional, plano diretor, produção do espaço, Fortaleza.

ABSTRACT: The housing question appears as essential element to understanding the production, consumption and appropriation processes of urban space, illuminating the relationship between sociospatial segregation and real state speculation that govern the brazilians' cities structuring. This paper proposes to discuss the relations between the Participatory Master Plan of Fortaleza (PDPFor) and the Municipal Housing Policy (PHIS), aiming to contribute to the reflection of the importance of the urban and housing policies integration. The text is divided into three parts: the first discusses the context of the emergence of the master plans "new generation" in Brazil; the second reconstructs the preparation process of the PDPFor and PHIS; and the third proposes a questioning about the dialogue between the urban and housing political, based on the analysis of the content of PHIS and housing policy chapter in PDPFor.

Key words: housing policy, master plan, space production, Fortaleza 


\section{INTRODUÇÃO}

O intenso processo de urbanização brasileiro foi resultado de uma industrialização incapaz de empregar a imensa massa de mão-de-obra disponível nas cidades, gerando um significativo "exército industrial de reserva", precariamente inserido nos circuitos de acumulação do capital. Esse modelo perverso de urbanização, intrinsecamente ligado à estrutura agrária concentrada - com grandes latifúndios improdutivos ao lado de inúmeros camponeses destituídos dos meios de produção - revela que os fluxos migratórios campo-cidade foram ditados muito mais por fatores de expulsão do campo do que por atração das cidades. Destarte, essas cidades foram socialmente produzidas a partir das relações conflituosas entre vários agentes ou sujeitos da ação, podendo ser reunidos em três: o Estado, como aquele da dominação política; o capital em suas múltiplas estratégias de reprodução (frações do capital industrial, comercial e financeiro e suas articulações com outros setores da economia, como o mercado imobiliário); e os "sujeitos sociais que, em suas necessidades e seus desejos vinculados à realização da vida humana, têm o espaço como condição, meio e produto de sua ação" (CARLOS, 2011, p.64). E como lembra Maricato (2001, p.51), "é impossível esperar que uma sociedade como a nossa, radicalmente desigual e autoritária, baseada em relações de privilégio e arbitrariedade, possa produzir cidades que não tenham essas características".

Entre tantos problemas resultantes dessa produção social das cidades brasileiras, este texto traz algumas reflexões referenciadas empírica e teoricamente na questão da moradia na metrópole Fortaleza, localizada no Nordeste brasileiro, mormente as relações entre as políticas habitacional e urbana, como parte do processo de planejamento na escala municipal.

O presente trabalho propõe-se a discutir as interfaces entre o Plano Diretor Participativo de Fortaleza (PDPFor) e a Política Municipal de Habitação (Política Habitacional de Interesse Social-PHIS), visando contribuir para a reflexão da importância da integração das políticas urbana e habitacional.

Os procedimentos metodológicos adotados foram análise crítica de documentos legais (Constituição Federal de 1988, Estatuto da Cidade, lei do PDPFor e lei da PHIS), leitura de relatórios técnicos e diagnósticos de subsídio à formulação do PDPFor e da PHIS e leitura de textos acadêmicos sobre o PDPFor e a PHIS, bem como sobre as questões urbana e habitacional.

Este texto estrutura-se em três partes, além desta introdução e das considerações finais: a primeira traz para o debate a centralidade da questão urbana a partir do resgate do contexto de emergência da "nova geração" de planos diretores, no seio do movimento pela Reforma Urbana que perpassou a aprovação do capítulo da política urbana na Constituição Federal de 1988 e do Estatuto da Cidade em 2001; a segunda toma como foco as relações entre a política habitacional municipal e o plano diretor, fazendo uma breve reconstituição dos processos de elaboração desses dois documentos legais; e a terceira discute as interfaces entre o PDPFor e a PHIS, levantando o questionamento quanto ao diálogo entre as políticas urbana e habitacional, a partir da análise do conteúdo da PHIS e do capítulo da política de habitação e regularização fundiária do PDPFor.

\section{DO RESGATE AO DEBATE: CONTEXTO DE EMERGÊNCIA DA “NOVA GERAÇÃO” DE PLANOS DIRETORES}

Para entender a "nova geração" dos planos diretores, cunhados de "planos diretores participativos" pelo Ministério das Cidades visando diferenciá-los dos prolixos e inexeqüíveis "planos diretores de desenvolvimento" das décadas de 1970 e 1980, faz-se importante remontar ao contexto de crescente precarização das condições sociais que caracterizou a urbanização brasileira, marcadamente a partir das décadas de 1950 e 1960. O crescimento econômico brasileiro no bojo de sua abertura aos capitais internacionais acabou forjando um "Estado do deixe-estar social" (FERREIRA e MOTISUKE, 2007), no qual, em relação à moradia, a "não-política" habitacional, expressa nos cruéis expedientes de reprodução social como ocupações, cortiços, favelas e autoconstrução em loteamentos irregulares/clandestinos, se constituiu em importante estratégia do capital para rebaixar os custos com a reprodução da classe trabalhadora (OLIVEIRA, 1982). As múltiplas estratégias desse perverso processo foram estudadas por Kowarick, que passou a chamá-lo de "espoliação urbana" (KOWARICK, 1979). 
As grandes desigualdades que foram se acumulando à medida que a urbanização perversa sem precedentes se consolidava no país começaram a conformar um contexto em que a questão urbana passou a figurar na agenda de debates e lutas sociais. Um marco reconhecido por vários estudiosos (MARICATO, 2001; CYMBALISTA, 2007; SOUZA, 2002; ROLNIK, 2001; BUENO, 2007) é o Movimento Nacional pela Reforma Urbana.

O Movimento Nacional pela Reforma (MNRU) articulou-se na década de 1980, retomando o termo "reforma urbana", desenhado na década de 1960, no seio das reformas de base promovidas no governo João Goulart. De acordo com Cymbalista (2007), o termo foi cunhado no Seminário de Habitação e Reforma Urbana, realizado em 1963, no Rio de Janeiro, lançado as bases para o Governo Militar criar o Banco Nacional da Habitação (BNH) em 1964, que contraditoriamente desmanchou a possibilidade histórica de se fazer a reforma urbana ao dissociar totalmente a questão habitacional da questão fundiária.

Cymbalista (2007) relaciona a grande força do MNRU aos nascentes movimentos sociais ligados à luta por habitação:

A principal diferença do movimento articulado na década de 1980 em relação às iniciativas anteriores de revisão do marco legal do planejamento e da política urbana no país era a correlação de forças políticas envolvida. $O$ movimento pela reforma urbana da década de 1980 foi articulado em torno dos nascentes movimentos sociais de luta por moradia, quefaziam parte dos novos interlocutores que surgiam no país naquele momento, pressionando por reformas em várias áreas do Estado. Os novos movimentos sociais foram atores fundamentais no processo de redemocratização brasileiro nos anos seguintes, e foram um fator fundamental para a criação de um tônus político para a negociação e aprovação de uma série de conquistas posteriores (CYMBALISTA, 2007, p.26).

Uma das principais conquistas do MNRU em sua articulação a outros movimentos sociais durante a década de 1980, no tocante à política urbana, foi a inserção do capítulo da política urbana na Constituição Federal de 1988 (artigos 182 e 183), resultado da Emenda Constitucional de Iniciativa Popular de Reforma Urbana, subscrita por mais de 130.000 eleitores (MARICATO, 2001). Todavia, em que pese a grande importância dessa conquista, os movimentos sociais e os estudiosos da questão urbana reconhecem as limitações do texto constitucional, principalmente o fato de vincular a aplicação dos instrumentos que garantem o cumprimento da função social da propriedade e da cidade à existência de uma lei federal e do plano diretor. Assim, a falta de auto-aplicabilidade dos dispositivos constitucionais representou um grande entrave às mudanças concretas nos rumos de nossas cidades.

A partir do texto constitucional, o plano diretor passa a figurar como "instrumento básico da política de desenvolvimento e de expansão urbana" (art. 182, § $1^{\circ}$ ), o qual deve definir princípios, estratégias e instrumentos de ordenamento da cidade, de modo a garantir o cumprimento da função social da propriedade. É importante ressaltar a limitação que os deputados constituintes impuseram ao estabelecerem que o princípio da função social da propriedade seria aplicável em municípios com mais de 20 mil habitantes, obrigados a elaborar um plano diretor, impondo-se a dependência de conhecimento técnico e de ação política das gestões municipais para definir os critérios para o cumprimento da função social da propriedade. Fato relevante é que quando a Constituição Federal foi promulgada apenas $50 \%$ dos municípios brasileiros tinham mais de 20 mil habitantes e em 2000, após a criação de novos municípios, esse número caiu para $30 \%$ do total.

Após a promulgação da Constituição Federal de 1988, mesmo no contexto de redemocratização do país e de descentralização administrativa, teve início a longa via crucis da lei que regulamentaria o capítulo da política urbana, aprovada somente 13 anos após a Constituição Federal, ficando conhecida como Estatuto da Cidade. Ainda em 1990, nasce o Projeto de Lei - PL 5.788/90, de autoria do senador Pompeu de Souza, que visava regulamentar o capítulo da política urbana, ao qual foram apensados outros 17 projetos de lei até sua aprovação em 2001 (MARICATO, 2001). 
Conforme Rolnik (2001), o Estatuto da Cidade estruturou-se em torno do reconhecimento de três problemas-chave da questão urbana brasileira: a irregularidade fundiária (favelização), a especulação imobiliária (retenção de vazios urbanos) e a cidade tecnocrática (falta de participação popular). Para cada problema-chave, elegeu-se uma bandeira de luta e definiram-se instrumentos para cada uma delas: regularização fundiária, combate à especulação imobiliária e gestão democrática da cidade.

O texto do Estatuto da Cidade reforça a centralidade do plano diretor, quando define que "a propriedade urbana cumpre sua função social quando atende às exigências fundamentais de ordenação da cidade expressas no Plano Diretor" (art. 39). Há um avanço considerável ao determinar que "o plano diretor é parte integrante do processo de planejamento municipal, devendo o plano plurianual, as diretrizes orçamentárias e o orçamento anual incorporar as diretrizes e as prioridades nele contidas" (art. 40, $\S 1^{\circ}$ ). O Estatuto da Cidade detalhou a definição de critérios para obrigatoriedade de elaboração de planos diretores participativos para alguns municípios, como previsto no art. 41 , levando a uma enxurrada de novos planos diretores, tidos como "participativos", visando se adequar às exigências de seu conteúdo mínimo, estabelecido no art. 42 , e aos procedimentos participativos previstos no $\S 4^{\circ}$ do art. 40 .

Outro marco importante na política urbana do Brasil aconteceu em 2003, com a criação do Ministério das Cidades, antiga demanda da articulação pela reforma urbana, que se estruturou nos primeiros três anos com "expressiva identificação com os setores progressistas da área urbana, [permitindo] implementar avanços estruturais importantes como uma política nacional de habitação, o Conselho das Cidades e o Fundo Nacional de Moradia" (FERRREIRA e MOTISUKE, 2007, p.45).

Traçado esse breve panorama do contexto de emergência dos novos planos diretores, discute-se a seguir o caso específico de Fortaleza, cujo espaço foi produzido por um histórico planejamento descolado da realidade de parcela significativa da cidade - a cidade real, reconhecida por Maricato (2000) como um "lugar fora das ideias", dialeticamente articulado à cidade ideal/legal, produzida por "ideias fora do lugar".

\section{RECONSTITUINDO O PROCESSO DE ELA- BORAÇÃO DO PDPFOR E DA PHIS EM FOR- TALEZA}

Antes de discutir o processo de elaboração do PDPFor e da PHIS, considera-se pertinente traçar um breve panorama da constituição da metrópole Fortaleza, à guisa de contextualização do leitor. Analisando a dinâmica socioespacial da metrópole Fortaleza da atualidade, marcada pela acentuada macrocefalia, é difícil imaginar que até o final do século XVIII, ela era apenas uma pequena vila sem nenhuma expressão econômica, tendo apenas o papel de capital administrativa do Ceará (COSTA, 2009). A hierarquia urbana cearense era relativamente melhor distribuída, destacando-se cidades como Aracati, Icó, Sobral (com função comercial, administrativa e de serviços), Crato (com função agrícola, administrativa e industrial) $\mathrm{Ca}$ mocim, Acaraú (com função comercial e industrial) e Quixeramobim (com função comercial e de serviços). Isso está ligado ao fato de que a formação do território cearense apresentou peculiaridades no contexto do Nordeste brasileiro, não se desenvolvendo a partir da lógica de estruturação do espaço denominada de rede dendrítica, fundada na cidade primaz litorânea (DANTAS, 2009).

Conforme Dantas (2009), o quadro de isolamento da capital só seria alterado em meados do século XIX, em face de mudanças de ordem político-administrativa - independência jurisdicional do Ceará em relação a Pernambuco e a abertura dos portos às nações amigas - e tecnológica - implantação de ferrovias e de navios a vapor, que impunham vantagens na utilização do porto de Fortaleza para drenagem de mercadorias. É importante lembrar a conjuntura internacional favorável em relação à exportação de algodão cearense para Inglaterra em virtude da Guerra de Secessão americana, que interrompeu o fornecimento dessa matéria prima. Desde então, houve a reconfiguração da rede de cidades cearenses, pautando-se na progressiva concentração de fluxos de pessoas, mercadorias e capitais em Fortaleza, enfraquecendo os centros interioranos: 
[...] transformações de ordem econômico-social e do sistema de transportes - as ferrovias no final do século passado e durante toda a primeira metade deste século, e as rodovias sobretudo a partir de 1950 - explicam a evolução de Fortaleza. As vias de comunicação vieram facilitar os contatos entre as regiões favorecendo, além das atividades comerciais, um intenso processo migratório para a capital. Este processo migratório, diretamente ligado aos problemas da economia rural do Estado, foi intensificado a partir de 1930, em parte por influência das sucessivas secas (1932, 1952, 1958 e 1970). (SOUZA, 2009, p.69).

Essas transformações contribuíram para o processo de metropolização em Fortaleza a partir de meados da década de 1970. A oficialização de Fortaleza enquanto Região Metropolitana foi do tipo compulsório, ou seja, instituída por força legal (Lei Complementar $\mathrm{N}^{\circ} 14 / 73$ ) na esteira das estratégias de centralização do poder na época do Regime Militar. Já "no que tange à realidade socioespacial, significa dizer que sua institucionalização deu-se antes que o processo de metropolização se manifestasse" (SILVA, 2009, p.15). A institucionalização da RMF ocorreu com fins preventivos, configurando-se como uma "metropolização antecipada".

Dessa forma, a constituição real da metrópole Fortaleza se deu posteriormente à sua institucionalização enquanto Região Metropolitana pela Lei Complementar $n^{\circ}$ 14/1973. Criada de forma compulsória no bojo da centralização política que caracterizou a Ditadura Militar, a RMF foi composta inicialmente pelos municípios Fortaleza, Aquiraz, Maranguape, Pacatuba e Caucaia. Na década de 1970, ainda não existiam indícios de complementaridade nas funções dos municípios da RMF, nem continuidade da mancha urbana ou de fluxos de movimentos pendulares significativos, ou seja, a metropolização ainda não havia se manifestado. Somente na década de 1980, iniciou-se a conurbação no vetor sudoeste de expansão, com os municípios de Caucaia e Maracanaú, que hoje até são os municípios mais integrados à metrópole.
A configuração territorial da RMF apresentou muitas transformações nos últimos 40 anos, ampliando-se em função de desmembramentos pela emancipação de vários distritos (Eusébio, Guaiúba, Itaitinga e Maracanaú) e da agregação de outros municípios à RMF, resultando em conjunto dispondo de temporalidades e espacialidades diferenciadas, com 15 municípios. A realidade socioespacial da RMF confirma o descompasso entre os recortes institucionais das regiões metropolitanas e a efetiva configuração do recorte de sua aglomeração. Poucos municípios são efetivamente integrados à metrópole, de modo que a porção intra-urbana da RMF é compacta (Fortaleza, Maracanaú, Caucaia, Horizonte, Pacajus e Eusébio).

Ainda considerando a constituição da metrópole, ressalta-se que a mancha urbana só ultrapassou os limites do município de Fortaleza na década de 1980, na direção sul-oeste, e na década de 2000 na direção leste-sudeste. Mas a produção do espaço nestas direções teve significativas diferenças: no vetor sudoeste, a expansão foi induzida pela construção de grandes conjuntos habitacionais ou loteamentos periféricos em Maracanaú e Caucaia, ao passo que o vetor sudeste está sendo induzido pela expansão da malha viária regional (e pela concentração de investimentos públicos e privados), atraindo o mercado imobiliário formal. Assim, o vetor de expansão oeste/ sudoeste configura-se como área de transbordamento da população de baixa renda para os municípios vizinhos (Caucaia e Maracanaú), enquanto o vetor de expansão leste/sudeste configura-se como área de transbordamento da população de média e alta renda para os municípios vizinhos (Eusébio e Aquiraz), como indicou Pequeno (2002).

Considerando o breve quadro de contextualização da formação da metrópole Fortaleza, destaca-se que o estudo das relações entre os processos de elaboração do plano diretor municipal e da política habitacional de interesse social para as cidades brasileiras ganha destaque à medida que a questão da regularização fundiária e do combate à especulação imobiliária entram na pauta das discussões da política urbana. No caso de Fortaleza, os números referentes à favelização evidenciam mais que a necessidade dos mesmos, indicando a necessidade de que estes processos estejam intrinsecamente associados. 
Ao longo das últimas décadas, observa-se o rápido crescimento das áreas de favela, do número de famílias, ampliando-se também a representatividade do número de habitantes em termos percentuais em relação à população total da cidade. Em 1973, foi realizado o primeiro censo de favelas de Fortaleza, que totalizou 81 áreas, onde viviam mais de 205 mil habitantes, significando mais de $20 \%$ da população de Fortaleza. Em 1991, outra pesquisa censitária realizada pela COHAB-CE, específica para assentamentos precários, contabilizou 540 mil pessoas em 314 áreas de ocupação, superando a marca de $30 \%$ da população fortalezense. Dados extra-oficiais obtidos junto à equipe responsável pela elaboração do Plano Municipal de Habitação de Interesse Social (PLHISFor) indicam a existência de mais de 620 favelas em Fortaleza abrigando mais de 160 mil casas. Tem-se observado um percentual de mais de $30 \%$ de coabitação em áreas de ocupação, assim como uma média de 4,5 pessoas por família, o que totalizaria mais de 900 mil pessoas vivendo em favelas. Complementa esta constatação, a presença de 20 mil famílias em áreas de risco, um déficit habitacional da ordem de 77 mil unidades, em contraposição à presença de 70 mil imóveis vagos.

Todavia, ao longo da história urbana de Fortaleza observa-se que seus processos de planejamento urbano desconsideraram a questão da moradia como um dos seus principais desafios. Os processos de planejamento urbano em Fortaleza podem ser reunidos em, pelo menos, cinco períodos: (1) Levantamento/ Cadastro; (2) Planos de embelezamento/viés higienista; (3) Planos de estruturação viária - que produziram as frentes de expansão urbana; (4) Planos com abordagem integrada - sob o viés da cidade moderna e funcionalista/tecnocrática, com foco nos zoneamentos; e (5) Planos diretores (PEQUENO, 2011). O período atual, mesmo apresentando significativos avanços em relação aos anteriores do ponto de vista da formulação técnica e do envolvimento social ao minimizar paulatinamente o enfoque urbanístico e de desenho que marcou os três primeiros períodos, traz marcas da falta de politização no processo de planejamento, como reconheceram Pequeno e Freitas (2011, p. 6-7):
Verifica-se que, apesar das diferentes abordagens adotadas para os processos de planejamento urbano empreendidos ao longo do século XX, alguns aspectos negativos podem ser mencionados como recorrentes e comuns a todos: a sua realização por consultores externos ao corpo funcional do município, desperdiçando oportunidades de promover a formação de recursos humanos municipais; a elaboração de diagnósticos superficiais, os quais induziram soluções inadequadas à realidade local; as proposições com caráter generalista, predominando diretrizes de planejamento sob a forma de recomendações em linguagem jurídica e índices paramétricos homogeneizantes que desconsideraram a diversidade sociocultural com a qual o espaço intra-urbano vem sendo produzido; a exclusão da cidade informal, inexistindo ações voltadas para o seu enfrentamento, indicando a dissociação entre a política urbana e habitacional, apesar do ritmo acelerado com que se deu o crescimento da favelização na cidade.

Tomando como pano de fundo a fase mais recente do último período (o dos planos diretores), esse tópico reúne as reflexões sobre a política habitacional municipal e o atual plano diretor de Fortaleza, remontando ao processo de elaboração de cada um deles, visando explicitar os conflitos, os interesses em jogo e os agentes envolvidos.

O contexto pós-aprovação do Estatuto da Cidade era de otimismo por parte dos movimentos sociais bem como dos setores acadêmicos comprometidos com as lutas sociais. Em Fortaleza, estava no momento de revisar o Plano Diretor de Desenvolvimento Urbano, vigente desde 1992. Assim, ainda em 2001, cedendo às pressões da sociedade civil organizada, foi contratada uma equipe multidisciplinar formada por professores da Universidade Federal do Ceará, classificada por notório saber, por meio de contrato com a Associação Técnico-Científica Eng. Paulo de Frontin - ASTEF. Essa equipe inicial mostrava grande comprometimento com as lutas sociais, mas retirou-se do processo em 2002, pois: 
[...] simultaneamente, o executivo municipal mantinha, em paralelo, a revisão da lei de uso e ocupação do solo, visando à liberação de gabarito em determinados eixos viários, favorecendo sobremaneira ao mercado imobiliário. Com isso, os consultores anteriormente convocados para a revisão do PDDU retiraram-se do processo, desfazendo a equipe da qual a universidade tomava parte, sendo essa substituída por outros consultores oriundos de escritórios de arquiteturae, em grande parte, associados ao ramo da construção civil (PEQUENO; FREITAS, 2011, pp.7-8).

A nova equipe contratada pela ASTEF conduziu o processo sob coordenação da equipe da Secretaria de Infraestrutura do município de Fortaleza (SEINF) sem nenhuma participação popular, enfrentando várias manifestações sociais exigindo transparência. Mesmo assim, no final de 2004, no fim da gestão Juraci Magalhães, o PL do Plano Diretor de Desenvolvimento Urbano Ambiental (PDDUA) foi enviado à câmara para votação, mas ampla mobilização social impediu que ele fosse votado (SOUSA, 2010). Esse momento de auge tecnocrático do planejamento de Fortaleza foi nacionalmente reconhecido, como lembra Cymbalista, ao analisar a experiência nacional dos novos planos diretores influenciados pelo Estatuto da Cidade:

O Ministério Público vem acolhendo denuncias e obstruindo processos realizados sem participação popular. Um caso emblemático é o de Fortaleza, cuja prefeitura, após construir um Plano Diretor "de gabinete", sem participação popular, foi alvo de intensa mobilização social que acabou por invalidar o processo, que teve que ser reiniciado e reconduzido a partir das diretrizes do Estatuto da Cidade. (CYMBALISTA, 2007, p.28)

Vale destacar que no mesmo ano em que começam os trabalhos de revisão do plano diretor (2002), iniciam-se os estudos para elaboração do diagnóstico habitacional de Fortaleza, realizados pelo Centro de Treinamento e Desenvolvimento - CETREDE como subsídio à formulação da Política Habitacional de interesse Social (PHIS).
A elaboração da política habitacional de interesse social tomava parte das ações previstas pelo convênio assinado entre a Prefeitura de Fortaleza e a Caixa Econômica Federal para implementação do Programa Habitar Brasil, em seu sub-programa de desenvolvimento institucional. Infelizmente, houve a terceirização para consultores externos, desperdiçando-se com isso a possibilidade de formação de quadros próprios pelo setor público. Atividades como a realização de um novo cadastro de assentamentos precários, adequação das leis urbanísticas municipais para as especificidades da habitação de interesse social, formulação de plano de intervenção, dentre outros, também seguiram o mesmo procedimento, decorrendo no baixíssimo impacto do programa frente à questão da moradia em Fortaleza.

Os processos de formulação do plano diretor e da política municipal de habitação foram conduzidos totalmente desconectados. Após dois anos de trabalhos que se utilizaram da participação social apenas no discurso, a PHIS foi aprovada pela lei $n^{\circ} 8.918 / 2004$, publicada no Diário Oficial do Município no dia 30 de dezembro de 2004, no "apagar das luzes" da gestão de Juraci Magalhães. Outro elemento a destacar é que a aprovação da PHIS se deu no mesmo ano da aprovação da Política Nacional da Habitação (PNH), que buscou integrar as políticas habitacional e urbana, utilizando os instrumentos previstos no Estatuto da Cidade segundo as orientações do incipiente Ministério das Cidades, mas não apresenta nenhum diálogo com ela.

O descolamento entre a política urbana e a política habitacional continuou mesmo quando se retomou o processo de revisão do plano diretor na nova gestão, tida como democrática e participativa, em 2006. Contratou-se o Instituto Polis para sua realização sob coordenação da Secretaria de Planejamento (SEPLA), passando a ser chamado de Plano Diretor Participativo de Fortaleza (PDPFor). As atividades de revisão do plano diretor seguiam uma exigência da ampla campanha nacional pela elaboração dos planos diretores, conduzida pelo Ministério das Cidades desde 2005, articuladas às fortes pressões locais dos movimentos sociais e de parte da Universidade. 
Entre 2006 e 2008, ocorreram as quatro etapas do PDPFor: 1) preparação do processo - capacitação dos técnicos e da população; 2) leitura da cidade (técnica e comunitária) - I Fórum do Plano Diretor Participativo; 3) construção coletiva da proposta - audiências públicas territoriais, audiências públicas temáticas e II Fórum do Plano Diretor Participativo; e 4) pactuação do projeto de lei - Congresso do Plano Diretor Participativo. Houve ampla utilização do discurso de participação popular, mas estudo de Moreira (2010) avaliou os graus de participação popular nas etapas do PDPFor, utilizando-se de metodologia desenvolvida por Sousa (2002), e chegou às seguintes conclusões: na primeira etapa houve consulta; na segunda, apenas informação; na terceira, parceria; mas na última e decisiva etapa houve manipulação. Ou seja, tivemos níveis participativos aceitáveis em alguns momentos, considerando o contexto local, principalmente no II Fórum do Plano Diretor Participativo, mas com pouca capacidade decisória final e pouca inclusão da população como um todo.

Como explicitou Sousa (2010), esse processo foi marcado por conflitos de interesses dos agentes envolvidos: 1) poder público (dividido internamente entre um segmento ligado à gestão anterior - SEINF e SEMAM - e um segmento mais progressista identificado com a nova gestão - SEPLA e HABITAFOR); 2) campo popular (entidades e movimentos que compõem a Rede Nuhab: o Movimento dos Conselhos Populares, Federação de Bairros e Favelas, Movimento de Luta nos Bairros, Cáritas, Comunidades Eclesiais de Base, Coordenação de Movimentos Populares, Movimento Ambientalista, dentre outros); e 3) empresários (liderado pelo Sindicato da Indústria da Construção Civil do Ceará - SINDUSCON).

A forte articulação do grupo de empresários liderado pelo SINDUSCON, ainda que só tenha aparecido no final do processo, teve peso suficiente para mudar os rumos das negociações e fragilizar as conquistas do chamado "campo popular". Um dos principais focos de conflitos era a delimitação e regulamentação das Zonas Especiais de Interesse Social - ZEIS, que serão discutidas na terceira parte deste trabalho.
Finalmente, em 2009, após oito conturbados anos de revisão do plano diretor, o PDPFor foi aprovado pela Lei Complementar 062/2009. É importante lembrar que no final de 2008, foi lançado o Plano Nacional da Habitação (PLANHAB), com horizonte temporal de 2009 a 2023, prevendo as estratégias, linhas programáticas e ações que nortearão a atuação pública na questão habitacional. Mesmo apresentando limitações, o PLANHAB representa um esforço de consolidação da política nacional de habitação que vem sendo delineada desde 2003, com a criação do Ministério das Cidades e fortalecida com a criação do Sistema Nacional de Habitação de Interesse Social (SNHIS) e do Fundo Nacional de Habitação de Interesse Social (FNHIS) pela lei $n^{\circ} 11.124 / 2005$. Uma das determinações do PLANHAB, que possibilita aos municípios se integrarem ao SNHIS e receberem recursos do FNHIS, é a elaboração dos planos locais de habitação de interesse social. Nesse sentido, desde meados de 2010, começou a ser formulado o Plano Local de Habitação de Interesse Social de Fortaleza (PLHISFor) no âmbito da Fundação HABITAFOR.

Essa reconstituição histórica ajuda a analisar os textos legais ao evidenciar os conflitos de interesses entre os agentes envolvidos em sua elaboração, dando pistas quanto à correlação de forças sociais que permeia sua (não) implementação.

\section{INTERFACE PDPFOR E PHIS: AS POLÍTICAS URBANA E HABITACIONAL DIALOGAM?}

Tendo claro o contexto de elaboração da política habitacional do município e do atual plano diretor, nesse tópico examinam-se os textos legais da PHIS e do capítulo da política de habitação e regularização fundiária no PDPFor, buscando vislumbrar se há diálogo entre eles. No final desse tópico, como desdobramentos dessas reflexões, a discussão toma por foco as ZEIS, entendendo-as como o principal instrumento que exige e pode viabilizar o diálogo entre as políticas urbana e habitacional. 
Um olhar sobre os textos legais: a PHIS e o capítulo da Política de Habitação e Regularização Fundiária no PDPFor

A leitura da PHIS revela que ela não incorporou os princípios e os instrumentos do Estatuto da Cidade, embora ele seja citado na lei (art. $3^{\circ}$ ). Isso é particularmente relevante considerando-se os marcos históricos na escala nacional - Estatuto da Cidade, Ministério das Cidades, PNH - que poderiam e deveriam ter influenciado a elaboração da PHIS, caso a correlação de forças sociais local fosse outra.

$\mathrm{O}$ art. $3^{\circ}$ da PHIS estabelece nove diretrizes gerais condizentes com o novo cenário de regulamentação legal, mas a análise criteriosa da lei mostra que não passa de um "discurso pleno de boas intenções presente em muito da nossa legislação" (MARICATO,
2001, p.103). Isto fica evidente no art. $4^{\circ}$, que delineia os princípios e as estratégias da PHIS de forma genérica o suficiente para dificultar sua implementação, na medida em que não prevê ações concretas, metas e/ ou prazos de execução. O quadro 01 sintetiza os princípios e as estratégias da PHIS e compara-as com as linhas programáticas do PLANHAB, que são melhor formuladas e aplicáveis. Vale ressaltar que a PHIS não define estratégias de desenvolvimento institucional, o que reduz as possibilidades de implementação consistente por agentes comprometidos a longo prazo com a política habitacional, em vez de agentes que mudam ao sabor das trocas de gestão. Fato curioso (na falta de outra palavra) é que no ano anterior à aprovação da PHIS havia sido criada a HABITAFOR, mas não há menção dela na lei em análise.

Quadro 01. Princípios e estratégias da PHIS em relação às linhas programáticas do PLANHAB

\begin{tabular}{|c|c|c|}
\hline Princípios da PHIS & Estratégias da PHIS & $\begin{array}{c}\text { Linhas Programáticas do } \\
\text { PLANHAB }\end{array}$ \\
\hline- & - & $\begin{array}{c}\text { LPA4 - Desenvolvimento } \\
\text { institucional }\end{array}$ \\
\hline $\begin{array}{c}\text { Garantia de oferta de habita- } \\
\text { ções, visando suprir a de- } \\
\text { manda reprimida e reduzir o } \\
\text { déficit habitacional }\end{array}$ & $\begin{array}{c}\text { Nossa Morada - produção de } \\
\text { novas moradias }\end{array}$ & $\begin{array}{c}\text { LPA3 - Produção e aquisição } \\
\text { da moradia }\end{array}$ \\
\hline $\begin{array}{c}\text { Intervenção em moradias pre- } \\
\text { cárias propiciando melhorias } \\
\text { construtivas }\end{array}$ & $\begin{array}{c}\text { Morar Melhor - promover re- } \\
\text { formas habitacionais e implan- } \\
\text { tar infraestrutura }\end{array}$ & $\begin{array}{c}\text { LPA2 - Melhorias habitacio- } \\
\text { nais }\end{array}$ \\
\hline $\begin{array}{c}\text { Garantia de moradia digna, } \\
\text { assegurando condições de } \\
\text { infraestrutura e acesso aos } \\
\text { serviços públicos }\end{array}$ & $\begin{array}{c}\text { Qualidade de Vida - integração } \\
\text { de assentamentos precários à } \\
\text { cidade formal, com ampliação } \\
\text { do acesso aos serviços urbanos }\end{array}$ & $\begin{array}{c}\text { LPA1 - Integração urbana } \\
\text { de assentamentos precários e } \\
\text { informais }\end{array}$ \\
\cline { 1 - 2 } $\begin{array}{c}\text { Garantia de estabilidade e de } \\
\text { permanência na moradia, de } \\
\text { forma segura e socialmente } \\
\text { incluída }\end{array}$ & $\begin{array}{c}\text { Viver Tranquilo - promover } \\
\text { regularização fundiária }\end{array}$ & \\
\hline
\end{tabular}

Fonte: Elaboração própria a partir da PHIS 
Além da fragilidade dos princípios e estratégias da PHIS, as três grandes lacunas desse documento legal são: 1) gestão democrática da política municipal de habitação de interesse social; 2) instrumentos previstos na legislação e a regulamentação desses instrumentos; e 3) definição dos parâmetros da habitação de interesse social.

Quanto à gestão democrática da política habitacional, a lei silencia quando deveria mencionar a necessidade da realização de audiências e consultas públicas na execução da política habitacional, bem como a realização de uma avaliação periódica desta política pela população do município, por exemplo, em momentos como da Conferência da Cidade. Nada se fala também em relação à necessidade de se criar um plano municipal de habitação para detalhar as ações a serem executadas.

No tocante à previsão de instrumentos para execução da política habitacional, a lei prevê apenas a Concessão de Uso Especial para Fins de Moradia e a alienação de terreno de propriedade do município (arts. 12-18), desperdiçando a oportunidade de utilizar instrumentos fundamentais como as ZEIS, a Concessão de Direito Real de Uso, a Autorização de Uso, Cessão de Posse, Usucapião Especial de Imóvel Urbano, Direito de Superfície, Transferência do Direito de Construir, instrumentos que devem ter sua forma de aplicação prevista na lei. Digno de nota é que no mesmo Diário Oficial de publicação da PHIS consta a lei no 8.923/2004, que cria o Plano de Regulamentação das ZEIS, mas as ZEIS não são nem mencionadas na PHIS, ficando patente a falta de diálogo dentro da própria política habitacional do município. A recusa de tantos instrumentos à disposição aponta para a desarticulação entre política habitacional e fundiária que pauta as ações do poder público.

Em relação aos parâmetros da habitação de interesse social, a lei só estabelece a faixa de renda da população a ser alvo das políticas de interesse social (zero a três salários mínimos, conforme art. 10), mas não explicita a pluralidade de formas de moradia precária que caracterizam esse público-alvo (favelas, cortiços, loteamentos clandestinos/irregulares, áreas de risco, conjuntos habitacionais/mutirões precarizados), demandando componentes diferenciadas da política habitacional.
Muitas falhas da PHIS foram minoradas ou sanadas no capítulo da política de habitação e regularização fundiária do PDPFor $\left(\operatorname{arts.} 5^{\circ}\right.$ e $6^{\circ}$ ), que figura entre as 10 políticas setoriais previstas no plano. Inicialmente cumpre ressaltar que já constituiu considerável avanço dedicar um capítulo à política habitacional e de regularização fundiária, por reconhecer a forte imbricação entre a habitação e a questão fundiária.

$\mathrm{O}$ art. $5^{\circ}$ do PDPFor estabelece 19 diretrizes da política habitacional e de regularização fundiária, que incorporam os avanços legais trazidos pelo contexto de emergência dos novos planos diretores, discutido na primeira parte deste trabalho, abrangendo três eixos: regularização fundiária, função social da propriedade e da cidade, e gestão democrática da cidade. Esses eixos também estão presentes nos objetivos do PDPFor ligados diretamente à questão habitacional, previstos no art. $4^{\circ}$.

Já o art. $6^{\circ}$ do PDPFor apresenta 17 estratégias prioritárias para a política habitacional e de regularização fundiária, muito importantes para a real implementação do plano diretor, mas muitas delas ainda não foram concretizadas, mesmo tendo o prazo previsto na lei. A título de exemplificação, podem-se citar: o plano da política habitacional e de regularização fundiária tinha o prazo de dois anos para ser elaborado, mas o PLHISFor ainda está em elaboração sem previsão para seu término; o diagnóstico das condições de moradia no Município, detalhando suas tipologias está em andamento no âmbito do PLHISFor; o desenvolvimento do Sistema de Informações Habitacionais (SIHAB) não tinha previsão de prazo no plano diretor e ainda está em estruturação no PLHISFor; o mapeamento bienal do solo urbano não edificado, subutilizado e não utilizado com o fim de induzir o cumprimento da função socioambiental da propriedade através da aplicação dos instrumentos urbanísticos e jurídicos previstos no Plano Diretor não está acontecendo, mas o PLHISFor prevê a criação do Sistema de Vazios Urbanos (SIVU), que talvez contemple esses dados; a instituição das ZEIS está enfrentando grandes entraves políticos para se realizar, não havendo nenhuma ZEIS instituída; o desenvolvimento da estrutura administrativa e a qualificação do corpo técnico da política de habitação e regularização fundiária ainda é deficiente, como atesta o fato de que o PLHISFor está sendo elaborado por apenas 11 técnicos da HABITAFOR. 
O Quadro 02 sintetiza os desafios e os instrumentos previstos no Estatuto da Cidade para responder a cada um deles, bem como sua aplicação no PDPFor e na PHIS. Observa-se claramente como o PDPFor foi tecnicamente melhor formulado que a PHIS, utilizando todos os instrumentos previstos no Estatuto da Cidade, enquanto a PHIS só prevê a concessão de uso especial para fins de moradia.

Um grande problema do PDPFor é que ele vinculou a aplicação de muitos instrumentos à regulamentação posterior, fragilizando o processo de planejamento participativo de uma política urbana que dialogue com a política habitacional. Fato é que desde 2009, dos planos setoriais complementares, apenas o PLHISFor vem sendo realizado; da mesma forma, do conjunto de instrumentos a serem regulamentados e implementados, somente uma ZEIS (Lagamar) encontra-se em processo de implementação desde meados de 2011 com a criação do seu conselho gestor. Chama atenção que este processo só veio a ser detonado por conta das pressões da comunidade e dos interesses vinculados às grandes obras vinculadas à mobilidade urbana para o acesso ao estádio de futebol (Arena Castelão) para a Copa de 2014.

Quadro 2. Desafios e instrumentos do Estatuto da Cidade na política urbana

\begin{tabular}{|c|c|c|c|}
\hline Problemas-chave & $\begin{array}{l}\text { Bandeiras } \\
\text { de luta }\end{array}$ & $\begin{array}{c}\text { Tnstrumentos específicos / aplicação no } \\
\left.\text { PDPFor ( }{ }^{(}\right) \text {e na PHIS }\left({ }^{2}\right)\end{array}$ & $\begin{array}{l}\text { Instrumentos } \\
\text { gerais }\end{array}$ \\
\hline $\begin{array}{l}\text { Irregularidade } \\
\text { fundiária (faveli- } \\
\text { zação) }\end{array}$ & $\begin{array}{l}\text { Regulariza- } \\
\text { ção fundi- } \\
\text { ária }\end{array}$ & $\begin{array}{c}\text { ZEIS } \\
\text { Usucapião especial de imóvel urbano } \\
\text { Concessão de uso especial para fins de moradia } \\
\text { Concessão de direito real de uso } \\
\text { Regularização fundiária } \\
\text { Operação urbana consorciada } \\
\text { Outorga onerosa do direito de construir } \\
\text { Assistência técnica e jurídica gratuita para as co- } \\
\text { munidades e grupos sociais menos favorecidos }\end{array}$ & $\begin{array}{l}\text { Planos nacio- } \\
\text { nais, regionais } \\
\text { e estaduais de } \\
\text { ordenação do }\end{array}$ \\
\hline $\begin{array}{l}\text { Especulação imo- } \\
\text { biliária (retenção } \\
\text { de vazios urbanos } \\
\text { e de edifícios } \\
\text { subutilizados) }\end{array}$ & $\begin{array}{l}\text { Combate à } \\
\text { especulação } \\
\text { imobiliária }\end{array}$ & $\begin{array}{c}\text { ZEIS } \\
\text { Parcelamento, edificação ou utilização compulsó- } \\
\text { rios } \\
\text { IPTU progressivo no tempo } \\
\text { Desapropriação com pagamento em títulos de } \\
\text { dívida pública } \\
\text { Consórcio imobiliário } \\
\text { Transferência do direito de construir } \\
\text { Direito de preempção }\end{array}$ & $\begin{array}{l}\text { território e de } \\
\text { desenvolvimen- } \\
\text { to econômico e } \\
\text { social } \\
\text { Planejamen- } \\
\text { to das regiões } \\
\text { metropolitana, } \\
\text { aglomerações } \\
\text { urbanas e mi- } \\
\text { crorregiões }\end{array}$ \\
\hline $\begin{array}{l}\text { Cidade tecnocráti- } \\
\text { ca (falta de parti- } \\
\text { cipação) }\end{array}$ & $\begin{array}{l}\text { Gestão de- } \\
\text { mocrática } \\
\text { da cidade }\end{array}$ & $\begin{array}{l}\text { Órgãos colegiados de política urbana, nos níveis } \\
\text { nacional, estadual e municipal } \\
\text { Debates, audiências e consultas públicas } \\
\text { Conferências sobre assuntos de interesse urbano, } \\
\text { nos níveis nacional, estadual e municipal } \\
\text { Iniciativa popular de projeto de lei e de planos, } \\
\text { programas e projetos de desenvolvimento urbano }\end{array}$ & $\begin{array}{l}\text { Planejamento } \\
\text { municipal }\end{array}$ \\
\hline
\end{tabular}

Fonte: Elaboração própria a partir do Estatuto da Cidade e de MARICATO (2001). 
Como resultado, as conquistas legais marcadas pelo ideário de novas práticas de planejamento participativo ainda não se materializaram em conquistas sociais concretas. Além disso, os instrumentos em si não podem resolver as questões sociais e nenhuma virtualidade técnica pode substituir o controle social sobre essa prática.

Nesse sentido, o principal avanço do PDPFor foi estabelecer um conjunto de instrumentos, ligados a princípios e diretrizes progressistas, que devem ser objeto de luta pelas forças sociais, constituindo-se numa verdadeira "trincheira de batalha" pela implementação de uma institucionalidade democrática e participativa. Um caso emblemático é a luta social pela inserção das ZEIS no PDPFor, discutida a seguir.

\section{ZEIS: uma ponte possível entre as políticas urbana e habitacional}

As ZEIS constituem um tipo especial de zoneamento, tendo regras específicas de parcelamento, uso e ocupação do solo, cujo principal objetivo é a inclusão da população de menor renda no direito à cidade e à terra urbana servida de equipamentos e infra-estrutura, tanto por meio da delimitação de áreas previamente ocupadas por assentamentos precários (as chamadas ZEIS ocupadas), quanto por meio da delimitação de vazios urbanos e de imóveis subutilizados (as chamadas ZEIS vazios), destinados à produção de novas moradias populares (BRASIL, 2009).

Este instrumento é utilizado no Brasil desde a década de 1980, antecipando-se à Constituição cidadã, de forma pontual em municípios cuja correlação de forças políticas era progressista e favorável às demandas sociais. São referências reconhecidas os municípios de Recife, Santo André, Belo Horizonte, Diadema e São Paulo. Um bom histórico das experiências das ZEIS no Brasil foi feito por Ferreira e Motisuke (2007).

A partir das experiências bem-sucedidas das ZEIS em alguns municípios brasileiros, logrou-se incluí-las como instrumento previsto na lei $\mathrm{n}^{\circ} 10.257 / 2001$, fortalecendo as bases legais para sua aplicação em nível local por meio dos planos diretores. De acordo com as duas principais pesquisas nacionais de avaliação dos novos Planos Diretores produzidos, coordenadas pelo sistema CONFEA/CREAs e pelo IPPUR/UFRJ, em parceria com o Ministério das Cidades, estima-se que cerca de $80 \%$ dos Planos Diretores contemplaram a criação de ZEIS, depois de aprovado o Estatuto da Cidade, embora apenas 30\% dos planos regulamentem ZEIS vazios (BRASIL, 2009).

Conforme Souza (2002), as ZEIS são importante instrumento para promover a "inversão de prioridades", passando-se a investir na parte da cidade que nunca havia sido reconhecida pelo planejamento tecnocrático. Rolnik (2001) entende que as ZEIS podem são o instrumento síntese das diretrizes e princípios norteadores do Estatuto da Cidade, pois atuam no enfrentamento dos três problemas-chave da questão urbana brasileira: o combate à especulação imobiliária, impedindo-se o remembramento de lotes e consolidando-se áreas de ocupação sob pressão do setor imobiliário formal; a promoção da regularização fundiária graças à flexibilização dos índices urbanísticos; a adoção de práticas de gestão democrática e participativa mediante a formação de conselhos locais que atuam nas diferentes fases de sua implementação.

O processo de inserção das ZEIS no PDPFor foi recentemente analisado por Pequeno e Freitas (2011), mostrando como esse instrumento foi alvo das principais disputas de interesses entre os agentes envolvidos na sua elaboração. Os autores evidenciam como a delimitação das ZEIS no plano diretor foi uma árdua conquista do campo popular, mediante a formulação de propostas bem fundamentadas dos movimentos e lideranças comunitárias capacitados por ONGs em parceria com setores engajados da Universidade. Essa conquista, todavia, foi limitada pela correlação de forças políticas local, fortemente ligada às pressões do setor imobiliário, como revela a falta do detalhamento necessário na regulamentação, adiando ainda mais as possibilidades reais de fazer cumprir a função social da propriedade e da cidade.

Nos artigos 124 a 133, o PDPFor classifica as ZEIS em três tipos: tipo 1(ocupações/favelas), tipo 2 (conjuntos habitacionais e loteamentos clandestinos) e tipo 3 (vazios urbanos / terrenos subutilizados), conforme o mapa a seguir (Figura 1). 
Figura 1. Zonas Especiais de Interesse Social - Fortaleza

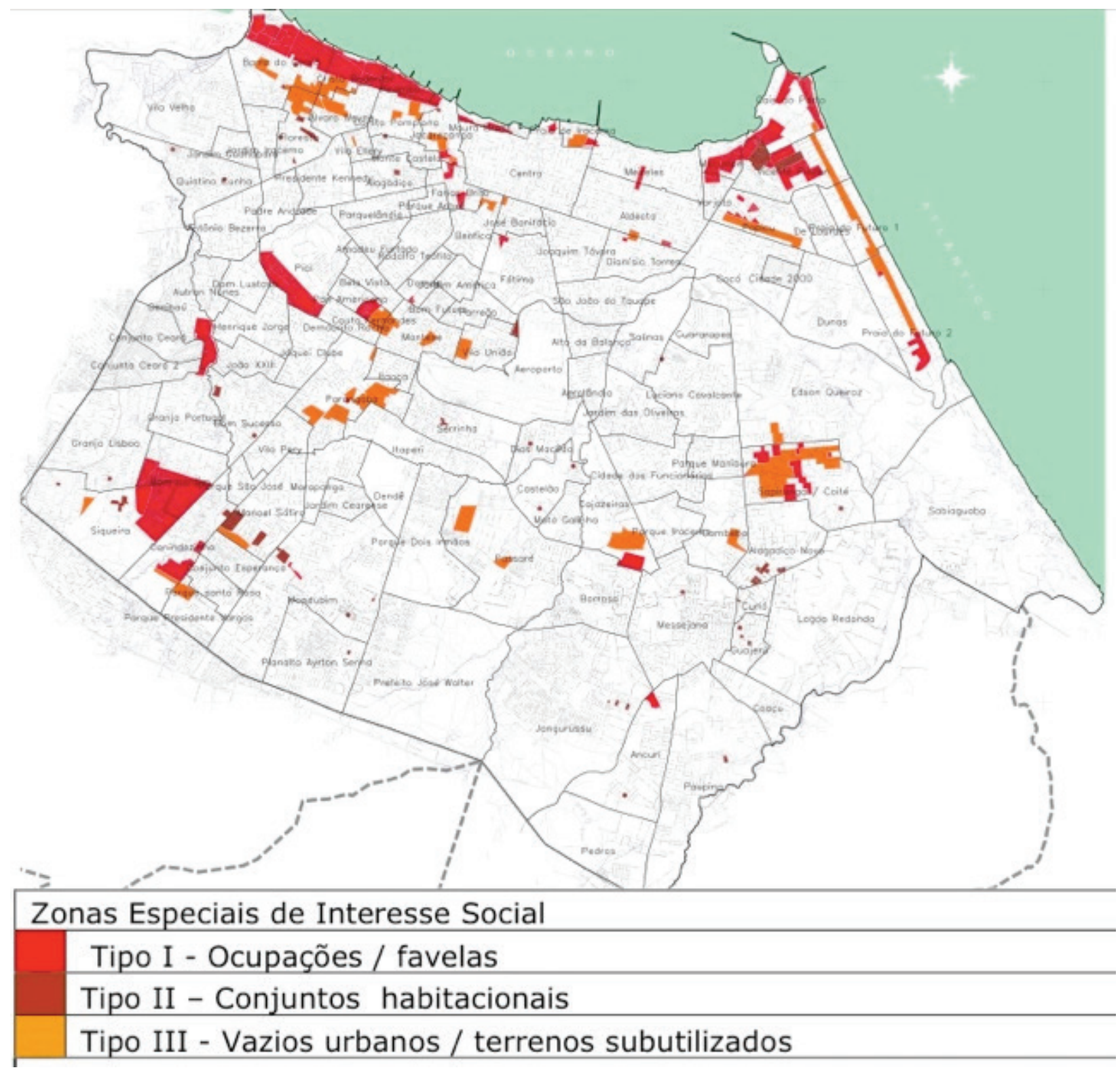

Fonte: Plano diretor de Fortaleza, 2007.

A espacialização das ZEIS torna evidente o subdimensionamento do problema habitacional em Fortaleza, que, segundo dados ainda não oficiais, está em vias de atingir o alarmante nível de $40 \%$ de favelização (PEQUENO, 2011). Ainda assim, ter essas primeiras 135 áreas delimitadas oficialmente (45 ZEIS 1; 56 ZEIS 2 e 34 ZEIS 3) já abre possibilidades reais de controle social dos rumos da política urbana em articulação com a política habitacional no município. Merece ser destacado que novas ZEIS podem ser anexadas através de projetos de lei específicos encaminhados pelo executivo, sem que se tenha que aguardar uma nova revisão do plano diretor municipal. Um dos principais pontos de fragilização das ZEIS em Fortaleza foi o fato de seu mapeamento ter sido publicizado em 2006, mas a aprovação do PPDFor só ter ocorrido em 2009. Vale ressaltar que a gestão municipal "congelou" as ZEIS favela já em 2006, não permitindo remembramento de lotes ou qualquer aprovação de novos projetos, mas não "congelou" as ZEIS vazio. 
O resultado perverso é que os proprietários e empreendedores imobiliários apressaram-se em aprovar projetos nas áreas delimitadas como ZEIS vazio, reduzindo o já pequeno montante de terras disponíveis para HIS.

Estudando as ZEIS no planejamento urbano, Pequeno e Freitas (2011) identificam processos associados à atual política urbana e habitacional de Fortaleza:

[...] a realização de empreendimentos imobiliários em ZEIS, o uso político das mesmas pelo poder local, a organização de parcerias público privadas associadas a mega-eventos, fragilizando os instrumentos, além do desconhecimento quanto ao conteúdo urbanistico e à diversidade das condições de moradia nas zonas especiais e nas vizinhanças. Todos eles indicam a presença de conflitos e disputas territoriais, onde os diferentes atores tendem a explicitar seus interesses, abrindo-se o debate em torno da questão fundiária. $\mathrm{Na}$ atual conjuntura, apesar da disponibilidade de recursos para produção habitacional pelo Estado, as dificuldades em obter terrenos para sua implementação demonstram que esse instrumento pode vir a ser adotado pelo Estado para ações de provisão habitacional. (PEQUENO e FREITAS, 2011, pp. 18-19).

Todavia, ainda que existam ZEIS do tipo vazio urbano, acredita-se na dificuldade de sua adoção para a implementação de programas habitacionais de interesse social. Observa-se que os empreendimentos imobiliários do programa Minha Casa Minha Vida vem sendo em sua maioria implantados nos municípios periféricos a Fortaleza, reproduzindo a mesma lógica do passado, associada aos grandes conjuntos do BNH nos anos 1970 e 1980. Ao mesmo tempo, remanescem as chamadas ZEIS vazios, sob a forte pressão do setor imobiliário, aguardando pelo vencimento do prazo dado, ou mesmo promovendo alterações na lei do plano diretor aprovada em 2009.
Essas breves reflexões permitem reconhecer as ZEIS como ponte possível entre as políticas urbana e habitacional, na medida em que articulem as ZEIS aos outros instrumentos de indução do desenvolvimento urbano. Em outros termos, somente uma política urbana pautada no cumprimento da função social da propriedade pode viabilizar uma política habitacional eficiente, prevendo os instrumentos de liberação de terras urbanas infra-estruturadas retidas pelo processo de especulação imobiliária.

\section{CONSIDERAÇÕES FINAIS}

A análise do contexto de elaboração das leis da PHIS e do PDPFor, bem como de seu conteúdo, conduz ao questionamento quanto ao diálogo entre as políticas urbana e habitacional. Evidenciou-se que o capítulo da política habitacional e de regularização fundiária foi melhor formulado que a própria lei da política de habitação municipal, o que deve ser entendido como resultado da correlação de forças sociais presente em cada momento que culminou na aprovação de ambos (2004 e 2009). Todavia, o PDPFor ainda deixou um longo caminho a ser construído e percorrido na luta pela implementação efetiva dos instrumentos de regularização fundiária e de combate à especulação imobiliária em suas diversas formas, fazendo com isso valer a função social da propriedade, dando tempo para que grupos ligados ao mercado imobiliário façam prevalecer seus interesses em detrimento dos interesses coletivos.

Além disso, a imensa dívida social acumulada pelas décadas de "espoliação urbana" em nosso país, especialmente nas metrópoles, exige mudanças mais significativas. Como Rolnik (2007) evidenciou, as grandes desigualdades que marcam nossas cidades foram produzidas, a despeito do que diz o senso comum, pelo planejamento perverso de apenas uma parte da cidade e até mesmo pela política habitacional implementada desde o BHN. As reflexões críticas sobre o PDPFor e a PHIS corroboram essa afirmação de Rolnik (2007), mas nem por isso se deve ceder à tentação de cair na "paralisia propositiva" ou negar-se a dar pequenos e insistentes passos enquanto não se consegue saltar o abismo, como assinalam os autores: 
[...] a questão estrutural [...] não deve diminuir a importância ou mesmo a luta pela implementação de políticas públicas que se proponham a inverter a lógica da prioridade dada às elites, que promovam a distribuição de renda, mesmo que de forma pontual ou efêmera. Esta é, em essência, a sintese do impasse em que se encontra a esquerda no Brasil e mesmo no mundo: a incapacidade de impor mudanças estruturais ao modelo econômico vigente, o que se reverte na retomada - pelas esquerdas mais frustradas com tal dificuldade - do anacrônico dilema de reforma ou revolução, que na prática acaba aniquilando qualquer interpretação de que políticas bem implementadas não são obrigatoriamente reformistas, mas podem ser bastante transformadoras. (FERREIRA e MOTISUKE, 2007, p.45).

Assim, mesmo mantendo a visão crítica e de longo alcance, avanços devem ser reconhecidos. Um exemplo é o PLHISFor, que, apesar de todas as limitações, aponta para uma mudança de paradigmas ao ser formulado pela instituição de habitação municipal (HABITAFOR), sem recorrer às consultorias externas, que geralmente faziam um diagnóstico superficial, com mera compilação de dados oficiais já existentes, sem produzir uma base de dados consistente sobre a cidade real, dificultando sua implementação pelo poder público. É importante destacar a forte relação do PLHISFor com as linhas programáticas do PLA$\mathrm{NHAB}$ e os avanços institucionais da escala nacional no sentido de buscar a integração entre as políticas urbana e habitacional.

Cumpre ressaltar que as ZEIS podem promover o diálogo entre as políticas urbana e habitacional, pois contrariam o discurso da indisponibilidade de terras para habitação de interesse social em virtude de seu alto valor. $\mathrm{O}$ âmago da questão reside na necessidade de liberação das terras infra-estruturadas retidas no processo de especulação imobiliária, o que seria alcançado caso as ZEIS vazio já delimitadas no PDPFor fossem implementadas. Desse modo, evidencia-se que há caminhos e instrumentos para "mudar a cidade", mas faz-se imprescindível o controle social sobre eles.

\section{REFERÊNCIAS}

BUENO, Laura M. Inovações para a concretização dos direitos à cidade: limites e possibilidades da lei e da gestão. In BUENO, Laura M.; CYMBALISTA, Renato (Org.). Planos diretores municipais: novos conceitos de planejamento territorial. São Paulo/Anna Blume/ Instituto Pólis/PUCCAMP, 2007, p. 11-24.

BRASIL. Constituição Federal do Brasil. Câmara dos Deputados, Brasília, 1988.

. Lei Federal $n^{\circ} 10257$, de 10 de julho de 2001. Regulamenta os artigos 182 e183 da Constituição Federal, estabelece diretrizes gerias da política urbana. (Estatuto da Cidade).

. Guia para regulamentação e implementação de Zonas Especiais de Interesse Social - ZEIS em Vazios Urbanos. Brasília: Ministério das Cidades, 2009.

CARLOS, Ana Fani Alessandri. Da "organização" à "produção" do espaço no movimento do pensamento geográfico. In: CARLOS, Ana Fani Alessandri; SOUZA, Marcelo Lopes de; SPOSITO, Maria Encarnação Beltrão (orgs.). A produção do espaço urbano: agentes e processos, escalas e desafios. São Paulo: Contexto, 2011, p.53-73.

CYMBALISTA, Renato. Instrumentos de planejamento e gestão da política urbana: um bom momento para uma avaliação. In BUENO, Laura M.; CYMBALISTA, Renato (Org.). Planos diretores municipais: novos conceitos de planejamento territorial. São Paulo: Anna Blume: Instituto Pólis: PUCCAMP, 2007, pp. 25-32.

COSTA, Maria Clelia Lustosa. Planejamento e Expansão Urbana. In: DANTAS, Eustógio Wanderley Correia; SILVA José Borzacchielo da; e COSTA, Maria Clélia Lustosa. De cidade à metrópole: (trans) formações urbanas em Fortaleza. Fortaleza: Edições UFC, 2009, p.143-185. 
DANTAS, Eustógio Wanderley Correia. Da Fortaleza à região metropolitana. In COSTA, Maria Clélia Lustosa e DANTAS, Eustógio Wanderley Correia (org). Vulnerabilidade socioambiental na região metropolitana de Fortaleza. Fortaleza: Edições UFC, 2009.

FERREIRA, João S. W. e MOTISUKE, Daniela. A efetividade da implementação das Zonas Especiais de Interesse Social no quadro habitacional brasileiro: uma avaliação inicial. In: BUENO, L. M..; CYMBALISTA, R. (Org.). Planos diretores municipais: novos conceitos de planejamento territorial. São Paulo: Anna Blume/ Instituto Pólis/PUCCAMP, 2007, p. 33-88.

FORTALEZA, (Prefeitura Municipal) Política Habitacional de Interesse Social - PHIS. Relatório de Diagnóstico da Situação Habitacional no Município de Fortaleza - Etapa II - Relatório Final. COMHAB - Comissão de Implantação de Projetos Habitacionais de Interesse Social e Infra-estrutura Urbana, Fortaleza, 2003.

Lei $n^{\circ} 8.918 / 04$, que instituí a Política Habitacional de Interesse Social do Município de Fortaleza. Fortaleza, 2004.

Plano Diretor Participativo de Fortaleza.

Relatório 2 - Leituras jurídica, urbanística e comunitária. Instituto Pólis/Prefeitura Municipal de Fortaleza. Fortaleza, 2006.

Plano Diretor Participativo de Fortaleza (Lei 062/2009), Fortaleza, 2009.

KOVARICK, Lucio. A espoliação urbana. Rio de Janeiro: Paz e Terra, 1979.

MARICATO, Ermínia. As idéias fora do lugar e o lugar fora das idéias. In: ARANTE, Otília; VAINER, Carlos; MARICATO, Ermínia. A cidade do pensamento único. Petrópolis: Vozes, 2000. p. 121-192.

Brasil, cidades, alternativas para a crise urbana. Petrópolis: Vozes, 2001.
MOREIRA, Arthur Felipe Molina. O processo de participação popular do Plano diretor de Fortaleza. (Apresentação). Observatório das metrópoles (sítio na internet). Disponível em http://www.observatoriodasmetropoles.ufrj.br/arthur_molina.pdf. Acesso: 20 de maio de 2011.

OLIVEIRA, Francisco de. O Estado e o urbano no Brasil. Espaços e Debates. n 6, São Paulo, 1982.

PEQUENO, Renato. Desenvolvimento e degradação do espaço intra-urbano de Fortaleza. Tese (Doutorado), FAU-USP, São Paulo, 2002.

PEQUENO, Renato; FREITAS, Clarissa Figueiredo Sampaio. Desafios para Implementação de Zonas Especiais de Interesse social em Fortaleza. ENCONTRO NACIONAL DAANPUR, Rio de Janeiro, 2011. Anais..., ANPUR, Rio de Janeiro, 2011.

ROLNIK, Raquel. Guia do Estatuto da Cidade. Câmara dos Deputados, Brasília, 2001.

. A construção de uma política fundiária e de planejamento urbano para o país: avanços e desafios. In BUENO, Laura; CYMBALISTA, Renato (Org.). Planos diretores municipais: novos conceitos de planejamento territorial. São Paulo: Anna Blume/Instituto Pólis: PUCCAMP, 2007, p. 271-283.

SILVA, José Borzacchiello da. Formação socioterritorial urbana. In: DANTAS, Eustógio Wanderley Correia; SILVA, José Borzacchielo da; COSTA, Maria Clélia Lustosa. De cidade à metrópole: (trans) formações urbanas em Fortaleza. Fortaleza: Edições UFC, 2009, p. 87-141.

SOUZA, Maria Salete de. Análise da estrutura urbana. In DANTAS, Eustógio Wanderley Correia; SILVA José Borzacchielo da; e COSTA, Maria Clélia Lustosa. De cidade à metrópole: (trans)formações urbanas em Fortaleza. Fortaleza: Edições UFC, 2009, p.13-86. 
SOUSA, André Lima. O Território da Habitação no Processo do Plano Diretor Participativo da Cidade de Fortaleza/CE, Brasil. Scripta Nova. Revista Electrónica de Geografía y Ciencias Sociales. [En línea]. Barcelona: Universidad de Barcelona, 1 de agosto de 2010, vol. XIV, no 331 (9). <http://www.ub.es/geocrit/ sn/sn-331/sn-331-9.htm>.

SOUZA, Marcelo Lopes de. Mudar a cidade. Rio de Janeiro: Bertrand Brasil, 2002. 